


\section{Experiencia ethoica e imaginarios sociales modernos. Contribución a una agenda pendiente}

Héctor García Cornejo Universidad Michoacana San Nicolás de Hidalgo

Resumen

Este texto contiene dos secciones, una sugerencia para la agenda propuesta por Lidia Girola para la investigación de imaginarios sociales y una lectura crítica de la plataforma conceptual de la teoría de los Imaginarios Sociales Modernos de Charles Taylor. Evalúa la idea tayloriana de que aclarando la autocomprensión de la modernidad modélica occidental comprenderemos las otras modernidades. Desde la teoría de Bolívar Echeverría, parece ser inaceptable esta explicación de la modernidad como modélica y múltiple, porque termina omitiendo las experiencias (mundos de vida de las múltiples) y que un patrón de dominio acompaña la modernidad occidental, lo que provoca el surgimiento de contra imaginarios. Con el concepto de Ethos histórico se exploran posibles imaginarios, especialmente de los que viven en la parte baja de la modernidad, omitida por Taylor.

Palabras clave: Imaginarios, cultura, Bolívar Echeverría, Charles Taylor. 


\section{Abstract}

This text contains two sections, one suggestion to the research agenda proposed by Lidia Girola on Social Imaginaries, and a critical reading on the Charles Taylor's conceptual platform of the Modern Social Imaginaries theory. It evaluates the Taylor's idea: clarifying the self-understanding of modernity in Western model, it is possible to understand the rest of the modernities. From the B. Echeverria's theory, seems to be unacceptable the explanation of modernity as single and multiple, because It ended up skipping experiences (worlds of life which belonged the multiple) and the fact that a domain pattern comes with Western modernity, which leads to arise some counter imaginaries. With the concept of the Historical Ethos is explored the possibles imaginaries, especially of those who live in the lower part of modernity, omitted by Taylor.

Keywords: Imaginaries, Culture, Bolivar Echeverría, Charles Taylor.

Habría pues, que intentar, este mismo tipo de acercamiento a su obra, riguroso, crítico, sistemático, pero a la vez, hereje y utilitario.

Carlos Oliva Mendoza

- ste texto se desarrolla a partir de una serie de preguntas sobre Ela comprensión de la modernidad que presentan Bolívar Echeverría y Charles Taylor: ¿cuál es su visión sobre ésta?, ¿qué justifica ambas teorías y cuál es su relevancia epistemológica?, ¿cuáles son los diversos resultados concretos de la modernidad en las diversas temporalidades y geografías y cuáles las tendencias y las perspectivas? Las respuestas nos orientarán respecto del conjunto de los ideales, usos, costumbres, formas de organización y sus institucio- 
nes, experiencias, formas de estructuración societal y fines sociales concomitantes a lo moderno. En lo que sigue, vamos a intentar responderlas mediante una lectura crítica de la posición de discurso que Taylor expone en su "Introducción" a Modern Social Imaginaries (para la exposición que sigue, cfr. Taylor, 2004: 1s). Ya que para Taylor, el problema de la ciencia social moderna es la modernidad misma, o sea, el advenimiento de un mundo contradictoriamente desarrollado, su propuesta es que en nuestros días (en que se considera el dilema sobre si estamos ante un fenómeno singular o múltiple, y que el segundo, no pueda enmarcarse en una teoría general de la modernidad) necesitamos cambiar esta perspectiva para darle salida a dicho dilema; no discutiremos, por lo menos no directamente, esta particular idea, que lo múltiple no es también modernidad, aunque sea perfectamente distinguible de la singular (single phenomenon). A Taylor, este planteamiento sólo le sirve para reconocer el hecho de que hay otras vías para modernizarse, pero, consideramos que estas diferentes vías han resultado en distintas experiencias y mundos de vida.

Taylor dice que las modernidades desarrolladas como fenómeno múltiple no pueden ser entendidas con las categorías de una teoría diseñada a partir del modelo que la considera un conjunto unitario de fenómenos, por lo cual, cabría entender que su teoría de los imaginarios sociales modernos no está diseñada a partir de ese modelo, pues considera diversos fenómenos. Su libro explora la hipótesis de que se puede echar luz sobre la comprensión de ambas versiones de modernidad si se puede llegar a una definición más clara de la autocomprensión que las constituye; pero, podemos preguntar: ¿bajo qué condiciones la autocomprensión es epistemológicamente pertinente? Para Taylor, la modernidad occidental es inseparable de cierto imaginario social, por lo que las diferencias entre las actuales múltiples modernidades necesitan ser entendidas en términos de los divergentes imaginarios involucrados; pero, no 
ve el hecho de que es igualmente inseparable de ciertas relaciones de poder, origen auténtico de las distintas modernidades.

Taylor dice no poner el concepto de imaginarios sociales por encima de las instituciones de la modernidad, sino que hace posibles sus prácticas donándoles un sentido; sin embargo, el sentido donado a las prácticas proviene de un set de ideas, imaginarios sociales modernos (ism); ${ }^{1}$ además, procede ocupándose únicamente de la concepción single y, con ello, cree poder comprender el sentido múltiple, sólo porque su teoría 'no estaría diseñada a partir del modelo singular'. Su hipótesis básica es que para la modernidad occidental es central una nueva concepción del orden moral de la sociedad, pero, al ocuparse sólo de la perspectiva single, no ve en cuáles sentidos va ésta, ni las relaciones de índole esencial establecidas con lo múltiple.

El proceso que origina los ism parte de una idea que se origina en las grandes mentes, pasa luego a estratos sociales y, eventualmente, a toda la sociedad, con lo cual, llegamos a la glorificación de los individuos pensadores, que no sería relevante sino porque esta mira desestima el papel de las mediaciones en la constitución de la discursividad. Para Taylor, la mutación de esta visión del orden moral en nuestro ism consiste en llegar a ser socialmente de ciertas formas (aunque veremos que se trata de algo más que de un orden moral), las cuales, esencialmente caracterizan a la modernidad occidental: la economía de mercado, la esfera pública y el pueblo auto-gobernado, entre otras; pero, en verdad, el patrón de poder moderno occidental es uno de "esos otros". A nuestro

${ }^{1}$ Discute este punto en el capítulo 3, pero, de forma insuficiente, a nuestro parecer, y distorsionando el materialismo histórico. Por el momento, no discutiremos esto, sólo que su perspectiva, a pesar de decir que no es idealista, metodológicamente sí lo es; pues, justamente, deja de lado el proceso histórico completo que llevó al surgimiento de ism y a que la autocomprensión de la modernidad sea considerada suficiente para explicarla y comprenderla. 
inicio, lo que está en juego es la capacidad operativa conceptual de dos ideas de Taylor: la primera es que esclareciendo la modernidad single comprenderemos la múltiple y, la segunda, es que la diferencia entre ambas está decisivamente marcada por sus diferentes imaginarios sociales. La primera delimitación que señala se vuelve en su contra, pues, examinar sólo lo relativo a occidente introduce serias dudas sobre extender la explicación al modelo múltiple, ya que fenómenos centrales han concurrido en la formación de eso múltiple de las modernidades. Vayamos por partes. La noción de imaginarios en el sentido de productos psicosociales que dan origen a instituciones sociales y que son factores estructurantes de sociedad, proviene de Cornelius Castoriadis (2013: 183ss), ${ }^{2}$ de modo, que la obra B. Anderson (1991), no es pionera. ${ }^{3}$ El problema de fondo con la teoría de Taylor es qué buscaba y qué consigue finalmente. Consiguió hablar sobre la parte encantadora y positiva de la modernidad, desde una posición plena y planamente eurocentrista; del lado oscuro, existente from the beginning en los propios centros del System-world, sólo escribió un par de líneas. ${ }^{4}$ Enseguida, sugerimos algunos temas y problemas para la agenda propuesta por Lidia Girola. Luego, reflexionamos más de cerca sobre la plataforma conceptual tayloriana, confrontándola con la teoría de la cultura de Bolívar Echeverría.

${ }^{2}$ En Estambul, publicó el volumen I de la obra entre 1964-65, mientras que el segundo, en el cual presenta el concepto de imaginario, en 1975. Aquí, me refiero a la última reimpresión, que incorpora ambos volúmenes.

${ }^{3}$ Para el estado actual de la discusión sobre imaginarios, ver Lidia Girola (2007: 45- 76): "Imaginarios socioculturales de la modernidad. Aportaciones recientes y dimensiones del análisis para la construcción de una agenda de investigación”. Relevante porque nuestro texto se conecta en relación con una agenda pendiente de investigación.

4 "[...] our sense of civilizational superiority and its possible relation to the persecution of scapegoats" (Taylor, 2004: 182s). Sendos lados oscuros como el colonialismo con toda su cauda de destrucción. 
En primer lugar, una nota central de los imaginarios es su ruptura con lo anterior. Se trata, en algunos casos, de una polarización respecto de lo previo, que va de lo simple a lo complejo. Por ejemplo, en la constitución del imaginario social moderno de la libertad, a partir de lo que suponemos como un imaginario social feudal (isf), el resultado es que, desde la capacidad de hacer hay que elegir sin sujeción a ningún orden jerárquico (cfr. Girola, 2007: 51). La diferencia con el libre arbitrio, isf (cfr. San Agustín, 1963: 249), es que de elegir bien, lo que Dios quiere, que es conformismo ante Su voluntad, el ism, al romper con el isf de la autoridad divina, se erige en inconformismo; de ahí a que el hombre (blanco, europeo) sea el maître et possesseur de la nature hay sólo un paso y solamente otro para la constitución del ism y sus acciones para el creciente control y manipulación tecno-científica de la naturaleza y del cuerpo social. Otro punto importante de los ism es el tipo de relación que se establece entre unos y otros, qué es lo que les da cohesión y unidad y si hay un núcleo estructurante unificador. Para Taylor ese eje es el 'sentido de civilización', aunque al decir que Europa se considera a sí misma su principal depositaria (2004: 179), aparece ya con claridad que el sentido último que legitima los ism es el principio eurocentrista. También, hay que considerar un 'background del background de los ism (cfr. Taylor, 2004: 3) que determina desde un mayor fondo una relación de legitimación entre una práctica y una idea. Luego, cabe preguntar, cuál es el contenido completo de los imaginarios y, si es posible, siguiendo a Castoriadis, pensar en un esquematismo (Kant) de la psique-imaginación productora de imaginarios. Más adelante, volveremos a esto. La investigación podría identificar imaginarios centrales y sus diversos tipos de ramificaciones en relación con la conformación de instituciones, experiencias, dominancias epocales y con otras formaciones dis- 
cursivas; así como los diversos momentos de choque entre el ism y dichas formaciones discursivas; su choque con las experiencias cotidianas de los mundos de vida y las dificultades para darles un sentido; el choque entre los mismos conjuntos del ism; las relaciones entre los ism y los procesos de secularización, pero no en el sentido del desplazamiento de la religión de la esfera pública o en el hecho de que la religión ocupa un lugar diferente (Taylor, 2004: 194), más bien en cómo se van integrando elementos profanos y religiosos, sus tensiones internas y el nuevo lugar de la moral en los espacios públicos y políticos, es decir, las nuevas formas de ejercicio de las dominancias y sus modos de justificación. Otro tema pendiente es el de las relaciones entre el ism y la industria cultural, cuál es su papel en la transformación o producción de nuevos ism y la diferencia de esta influencia entre en los países del centro y los de la periferia.

Hay que preguntar tanto sobre las formas y los modos de propagación de los conjuntos de nociones que dan origen al ism, como de la propagación de estos: cómo ambos son introyectados en las mayorías como dadoras de sentido a prácticas, qué les da fuerza y qué las acompaña como promesa. En cuanto nociones y en cuanto ideas donadoras de sentido a prácticas hay un significado peyorativo y uno meyorativo del ism, su oscuridad siniestra, atroz, y su claridad soleada, libertaria.

La confrontación de la teoría de Taylor con los ism de la modernidad Latinoamericana proporciona una visión más amplia de sus componentes — representaciones, ideales y valores (cfr. Girola, 2007: 68). Una visión más profunda, por su parte, podría darla una teoría semiótica materialista de la cultura, como se propone aquí. Con lo cual se puede comenzar una caracterización preparatoria de la experiencia ethoica y la descripción de sus posibles correspondientes 'imaginarios'. Lo primero es no omitir que la relación entre estructuración societal y de constitución del ism en América 
Latina es distinta de la que se dio en el modelo originario, sobre todo, en la dependencia económica y política sustentadas a lo largo de los siglos XIX y XX por el poder militar. Pensamos en una esfera pública inmadura y patológica debido tanto a las relaciones de poder, como a la carencia de instrucción; en unos malogrados autonomía y dominio, ${ }^{5}$ o un dominio desde un estado simulado, de lo que se deriva una grave inseguridad generalizada, y en una profunda desigualdad social con el importantísimo problema de la pobreza extrema. En cuanto a la democracia, actualmente, el crimen organizado decide sobre vidas, patrimonios y políticas públicas. 'Democracia con crimen organizado' es el estado-ficción que tiende a la anulación tanto de la esfera pública como de la política. Los procesos democráticos se revelan al final como una simulación opresiva. La sólida introyección de un background religioso rematiza casi cualquier proceso de secularización del ism. La constitución de la sujetidad es crecientemente determinada por el trabajoconsumo valorizado. Se confronta lo positivo de la propuesta de vida moderna contenida en los imaginarios contra lo negativo de la realidad de las prácticas a las que 'da sentido'.

Una ampliación de las preguntas de Girola sobre nuestra imagen en nuestros ism también puede ser clarificadora: ¿cómo nos vemos y cómo nos hemos visto a nosotros mismos, en qué sentido existimos y en cuáles hemos existido, cuáles son nuestras formas de aceptación y convalidación de la realidad de América Latina? (Girola, 2007: 71). La modernización ha tenido un impacto negativo en la formación de nuestra identidad cultural y, por tanto, nuestra relación respecto de los ism es no sólo conflictiva y traumática sino aniquiladora de la vida social (Girola, 2007: 72); el problema con la consideración de múltiples modernidades es que no sólo hemos

\footnotetext{
${ }^{5}$ Autonomía de los seres humanos, en el sentido del conocimiento y la acción, y dominio o rectoría, como las formas de inteligibilidad y modelación del mundo social y control y aprovechamiento del natural (cfr., Wagner, 2012: 22).
} 
partido de condiciones distintas y llegado a resultados distintos, sino que esta noción tiene su dosis de ideología; pues, lo múltiple encubre la sujeción al centro, la subordinación al sistema-mundo del cual somos insumo para su tipo de vida. Lo múltiple es, ciertamente, indicativo de los grados de dominación, antes que de la diferencia en cuanto a tipos de lo moderno. Empero, no descartamos cierta pertinencia de la noción de modernidades múltiples, para averiguar la formación de múltiples imaginarios asociados en cada caso, la realidad existente de las prácticas, o bien, su sentido de crudeza para los que vivimos en el suelo de la modernidad, a 70.000 brazas por debajo de su discreto encanto. En la propuesta de agenda, también habrá que tomar en cuenta la serie de fenómenos asociados con el globalismo, la globalidad y la globalización y su relevancia para la investigación de las especificidades más actuales que concurren en la constante variación formativa de imaginarios. ${ }^{6}$ Por último, pueden incorporarse a las sugerencias el papel de los poderes factuales en relación con los ism, la relación entre los imaginarios sociales y los mitos, el contenido mítico de los imaginarios y el contenido imaginario en los mitos.

La parte del trabajo respecto al análisis crítico de imaginarios propuesto por Taylor desde la perspectiva de Bolívar Echeverría, puede ser resuelto con la descripción y la interpretación de los ism de cada uno de los ethé de la modernidad, bajo la perspectiva de su teoría general de la cultura. La otra parte, esta agenda un tanto abundante, con su estudio sistemático, pero, requiere de todo un grupo de investigación y, en primera instancia, la decisión teórica de situarse fuera del esquema epistémico del principio del eurocentrismo. Dado que el primero es más viable, por ahora, dibujaremos algunos de sus contornos.

${ }^{6}$ Para una clara discusión crítica de estos conceptos ver Ulrich Beck (1997). 
Los ism como productos culturales (psicosociales) son relativamente estructuradores de la vida social y son producidos en el ámbito constituido por personas, cosas, ideas y básicamente tienen como emplazamiento un esquema epistémico civilizatorio eurocentrista, siendo todos los ism producto de las mediaciones sociales. El planteamiento de Girola, imaginarios socioculturales, integra un campo desestimado por Taylor: la cultura como instancia co-formadora de imaginarios. Es importante, no perder de vista el modelo de la modernidad - temporal y espacialmente datado — tanto de la teoría como de los imaginarios correspondientes, pues, nos servirá para la ponderación de los imaginarios y las realidades asociadas propias de América Latina (Girola, 2007: 48). Un problema que se discute en las últimas décadas es si estamos saliendo de la modernidad y si hay una diferente en cada país del orbe. Hay distintas discusiones, que van de la crítica postcolonial al postestructuralismo y ahí a los defensores de la modernidad y, en un extremo radical, a unos pocos que observan que se trata de una crisis terminal civilizatoria. Para Bolívar Echeverría, hay un factum: el hecho capitalista al cual (aclarando que no privilegia una última instancia fincada en las relaciones de trabajo) podemos llamar un 'factum civilizatorio' (1998: 37s.), lo que podría evitar entenderlo como un reduccionismo economicista y pone a la luz su multiplicidad como eje explicativo antes de acudir a su definición de la cultura. Este factum es el núcleo básico de la estructuración societal capitalista, lo que significa que es el acto fundamental de su modo histórico de producción y consumo, es decir, que lo funda y que se repite nuevamente cada día (cfr. Marx-Engels, 1971: 15). Es el esquema cultural introducido como un nuevo impulso histórico, pero, decir cultura es hablar del "cultivo dialéctico de la singularidad de una forma de humanidad en una circunstancia histórica determinada" 
(Echeverría, 1998: 161). Hay que decir de una vez que se puede entender la idea de última instancia como el campo en el que se decide la supervivencia o la extinción de lo orgánico, escasez absoluta significa la muerte y entonces ¿Cuál cultura? ¿Cuál esfera pública? ¿Cuál vida política? ¿Cuál colonialidad? ¿Cuál "otredad epistémica”? (cfr. Castro y Grosfoguel, 2007: 20). Esto es relevante al reflexionar sobre la experiencia cotidiana que viene como un paquete complejo de distintas experiencias, imaginarios, relaciones y actitudes. Así, podemos plantear la pregunta:¡cómo se constituye la experiencia en la complejidad de la vida moderna capitalista, o mejor dicho, en qué consiste este factum? La subsunción del valor de uso al valor de cambio es el acto fundativo y fundamental que produce una contradicción co-originaria, desde el suelo material en que se pone en práctica ese modo de civilización, i. e., que es la creación de riqueza mediante la alienación del plusvalor a las fuerzas sociales de trabajo. Lo que hay que distinguir, para una crítica de su actualidad, son los diversos tipos en que se han transformado este par de condiciones luego del fin del socialismo real y de la aparición del posmodernismo y la globalización; pero, el mundo moderno, aún funciona básicamente así: valorización del valor, explotación y aniquilación de cuerpo social. A partir del acto histórico fundamental, producción /consumo, se originan diversas subcodificaciones, hay, así, una forma 'natural' transhistórica, originaria de esta producción. ${ }^{7}$ Es necesario recordar esto, porque el modo moderno subsume este modo natural de codificación al propio de subcodificar, lo que es otra cara de aquella subsunción. En efecto, de esta forma natural transhistórica, surgen los tipos de sociedad; es decir, del modo en que se resuelve el cómo y el qué pro-

7 "El primer acto histórico de estos individuos, merced al que se distinguen de los animales, no consiste en qué piensan, sino en qué comienzan a producir los indispensables medios de su subsistencia” (Marx, 1971: 15). Y aquí no hay ningún eurocentrismo, pues la especie completa funciona de este modo. 
ducen, surge materializado, en cada caso, un determinado modo de manifestar la vida de los individuos y de sus mundos; lo que resultan ser, coincide exactamente con su modo de producción. El término 'producción', se refiere a todo lo que los individuos producen, desde los objetos más rudimentarios hasta los más finos productos del espíritu, pasando por la reproducción de la especie y no sólo a la producción en el sentido unilateral del trabajo (cfr. Marx, 1971: 16). Estamos hablando de que esta producción es, de otro modo, el nicho orgánico societal universal / particular de formación de los seres existentes en una determinada época concreta (sobre la base de su mismidad en constitución) y de su autoafirmación que la resignifica cada vez (cfr. Echeverría, 1998: 161s.). Bolívar Echeverría toma esta concepción de trabajo/disfrute para su propia construcción que, desde luego, no se aleja de la de Marx, sino por el contrario, la profundiza en el sentido de la producción natural, transhistórica; es decir, atendiendo a su sentido originario, no subsumido por la valorización del valor. La idea de que si los individuos son algo depende de las condiciones materiales de su producción, será reelaborada por Echeverría así: dicho ser resultante, espontáneo, se constituye en estas condiciones materiales en un conjunto de procesos de producción y consumo de signos. Estamos, en verdad, ante un esquema transcivilizatorio, con las características de necesidad de supervivencia, de trabajo, consumo, producción, de códigos y de lenguajes, todas constituidas en una compleja red de mediaciones, y no es que se trate de una formación ideológicamente neutra, sino que carga su propia ideología según el camino que tome la historia. 


\section{IV}

\section{A. Códigos: formas natural y epocal}

Detengámonos en el proceso de producción societal para ver cómo se configuran las subcodificaciones respectivas. Es relevante que este proceso ininterrumpido de trabajo/consumo es dialécticamente concomitante con un conjunto diferenciado de impulsos históricos —en donde uno resulta vencedor-. Una mismidad en ese despliegue, que en la situación concreta de resolver el conflicto inherente a la vida, resignifica los impulsos en la expresión de una cultura, constituida por experiencias y mundos de vida contradictorios, que son al mismo tiempo las distintas moradas y armas culturales que forman conjuntos de dominancias y compiten entre sí. Para Taylor, los ism dan sentido a prácticas, legitiman un modelo de civilización, provienen de la teoría de la moral y contienen apertura proyectiva a mundos de vida, a formas de experiencia; luego, ganan terreno en la mente de las masas y se convierten en ideas donadoras de sentido, dotadas de normatividad. Pero, falta mencionar el dark side of the modernity, y es que el sistema de las ideas y sus usos constituye el discurso de una dominancia ethoica: dentro del esquema estructural que se puede derivar de las premisas de Marx, en el que un aspecto central es la propiedad del trabajo social y la autoridad asociada, podemos decir que los propietarios de los vehículos de difusión y del material mismo, de ism, en efecto, viven la experiencia de un ethos dominante en la sociedad, el realista en cada caso. Esto significa que son afines y participan en el impulso conflictivo histórico-dominante. En la necesidad de resolver el conflicto inherente a la existencia, tenemos que desde sus diversos tipos de contradicciones societales se entra en un impulso histórico, el cual se interioriza y se responde, pero, depende de lo 
cultural , es decir, de ciertas subcodificaciones materializadas como mundos de vida y de sus posibilidades de re-sustancialización.

Los impulsos históricos modernos, fuerza histórica cultural dominante, que son productores de otras subcodificaciones, materializaciones $y$, por ende, de formas y modos de pensar, y de sentir que la existencia tiene un sentido, son los siguientes: de afirmación, de negación, de distanciamiento y de rebeldía. Esto es, conjuntos de ideas donadoras de sentido a las prácticas que afirman el mundo de la vida tal como se constituye, que lo niegan, que toman distancia o que se rebelan. Así, las preguntas son ahora, respecto de lo existente, los ism ¿qué afirman?, ¿qué niegan?, ¿de qué y cómo toman distancia? y ¿cómo y de qué se rebelan? Más adelante, intentaremos responderlas. No es que haya una realidad como tal, sino experiencias y mundos de vida construidos a los que se les ha dado un sentido, pero hay algo que es válido para todos y que concierne a las acciones y las condiciones de vida material y cultural de los individuos. Nos referimos al paquete completo de la experiencia cotidiana y los mundos de vida. Por otro lado, los ethé son pensados por Echeverría, a partir de su pureza y su coherencia, así, habría que preguntar a Taylor ¿con qué deben ser coherentes y puros los ism? Se trata del viejo problema de la consistencia entre pensar y ser. Hay tres formas sociales de ser sobre las que se edifican lo ism (Taylor, 2004: 2) y que, a la postre, resultan ser su objeto: economía, esfera pública y democracia. La evaluación crítica, tanto de los imaginarios determinados como de la realidad a la que dan sentido, comienza con la contrastación entre su contenido y dichas prácticas asociadas. Respecto a éstas, preguntamos: ¿quiénes se benefician con el mundo resultante? En forma sumaria, la economía es concebida con una lógica propia y legitimada (por donación de sentido) por su capacidad de traer bienestar y abundancia; la esfera pública es legitimada por su capacidad de desarrollar la incidencia de los individuos en la vida pública, lo que podríamos llamar el 
'principio ágora', y la vida democrática es legitimada por su capacidad de dotar de soberanía a los comunes y por una gama creciente de derechos. Todas estas prácticas están a medio camino o en vías de realizarse para las múltiples modernidades, no sólo en franca contradicción con lo existente sino que también, al donarle sentido, lo legitima. En el fondo, hay un background del background que da sentido - legitima y justifica - a los ism y a las prácticas, a saber, que Occidente es el depositario, productor y custodio de la civilización y sus sentidos. Así, la teoría de Taylor no sólo describe una forma de pensar y de vivir, sino que se convierte en su apologista y, con ello, queda atrapada en una determinación epistémica desde una particular concreción social histórica. Por lo tanto, al carecer de una formulación crítica que le proporcione una conciencia de esto, pierde validez como teoría. No hay ni coherencia, ni pureza entre los ism y las prácticas a las que da sentido, o bien, sí hay, pero, parcializadas.

Vayamos ahora a una revisión igualmente breve de la codificación y subcodificación por la que ha de tasarse la actividad humana de producción consumo. Se trata de un proceso natural o transhistórico originario del comportamiento vital — situado en los esquemas naturales que comparte con los animales (Echeverría, 2012: 160s)_, en el cual, las sociedades han de resolver el problema central para el telos de la supervivencia: qué hay para producir y qué se requiere producir. Se desenvuelve aquí un esquema básico con factores como necesidades vitales, trabajo, consumo, determinados por lo que hay en el territorio, por lo que se requiere y por el grado de avance civilizatorio. En el código, hay significaciones primarias sobre la división de género que introducen la primera división del trabajo, de la propiedad, de la forma política del grupo, de su fuerza frente a lo Otro, de la reproducción, del nacimiento, del crecimiento, de la muerte, de la escasez o de la abundancia, del dolor o el placer y del temor o la seguridad. En este nivel estamos 
aún en "la esfera profunda del 'lenguaje de la vida real', allí donde se produce el discurso, el 'lenguaje propiamente dicho', es decir, 'la conciencia y las ideas"” (Echeverría, 1976: 48). Podemos decir que hay una co-condicionalidad entre el código y el grado de desarrollo de los medios y las fuerzas de producción y que, ya en la específica construcción espontánea de mundos de vida y experiencias, estamos en el nivel de la subcodificación. Pero, hay también formas de experiencia digamos de tipo secundario, de índole meta-funcional respecto del impulso histórico vigente civilizatorio, en las cuales se realizan actividades no-reproductivas, y rompen el telos pragmático "indispensable para la supervivencia de la comunidad" (Echeverría, 2012: 51). Éstas son igualmente producidas por procesos semióticos a la vez que los producen, se trata de momentos lúdicos, rituales festivos o dramatizaciones estéticas y son relevantes para la formación correspondiente de imaginarios sociales respecto del trabajo / producción, por un lado, y respecto del juego / fiesta / arte, por el otro.

Poner en la base de formación de los ism la vida económica y política (Taylor, 2004: 2) nos lleva a otro grupo de preguntas: ¿Sobre qué tipo de orden moral previo surgen estas formas sociales: economía de mercado, etc.? Y, ¿qué tipo de imaginario previo al moderno hizo posible su surgimiento? Responder esto requiere el estudio del 'factum feudal', del isf y de cómo el nuevo impulso histórico subsumió a los existentes y el tipo de cultura que resultó de ello. Por otro lado, considerando el proceso de formación de los imaginarios, volvemos al hecho de que éstos resultan de otro más general: el de la formación material de semiosis. Sistemas de signos originados durante la des-sustancialización y re-sustancialización de la mismidad dan origen a imágenes determinadas por ésta. Al parecer, hay un "esquematismo» (Kant, 2005: 129) de la semiosis material: formas puras de pensamiento que subsumen la vida material intuida dan como resultado todos los imaginarios 
que hacen posible las prácticas (pero, con esta afirmación, quedaría el problema de si hay un esquematismo práctico del poder y qué pasa con los resultados de las acciones morales, que quedan en el terreno de la pura indeterminación, ya que esa es la relación entre las elecciones de la voluntad y sus resultados en el proceso de la existencia). ${ }^{8}$ El todo de la vida social proporciona el material para la subcodificación de todo lo que constituye la cultura, entendida como un comportamiento de configuración crítica de las identidades resultantes de este proceso de producción/consumo de significaciones. Tenemos así, ciertamente, el Factum general = el hecho de la existencia que ha de ser preservada y el Factum especial = los hechos nucleares de cada época en la historia de la sociedad. Estamos hablando de los hechos constitutivos societales cuya unidad está conformada por "todas las operaciones que la reproducción social del ser humano requiere" (Echeverría, 2001: 19), tanto aquellas que la sociedad capitalista ha logrado 'decantar' de su producción / consumo - las estrictamente necesarias para este fin-, como de toda la construcción simbólica que las rodea, aún en el mundo capitalista desencantado. Vemos, con esto, que la teoría de la modernidad como experiencia de Bolívar Echeverría tiene el alcance de una teoría general de estructuración sociohistórica de la especie humana. Los distintos modos de semiosis material resultan en distintos modos de conducir el cuerpo social como totalidad; no obstante, hay diferencias en la distribución del trabajo y, por tanto, del consumo. Con otras palabras: al vivir hay tipos distintos de experiencia de lo moderno. Una premisa importante es que en toda sociedad de clases la vida resulta dańada y, de algún modo, se vuelve insoportable. Por ello, los miembros sobre los que recae la edificación y preservación material de un mundo social — más que los beneficiados — han de hacerse de una estrategia como arma y

${ }^{8} \mathrm{O}$ "es algo de lo que no se ocupa la crítica, la cual investiga solamente si la razón pura puede ser práctica” (Kant, 2005: 54). 
como refugio para hacer vivible y soportable el daño continuo a la vida, su cotidiana miserabilidad. ${ }^{9}$ Como arma para hacerle frente y que no resulte en la aniquilación —que tiene en su base todo dominio-; como refugio para resguardarse del daño. La estrategia — arma y refugio - consiste en la interiorización de las contradicciones societales y en proporcionar una respuesta que permita la supervivencia. ${ }^{10}$

\section{B. Ethos histórico y experiencia moderna}

1. ¿En qué consiste lo insoportable de la vida moderna capitalista? $\mathrm{Y}$, ¿es insoportable para los cuatro tipos de ethé descritos por Echeverría? No hay una respuesta unívoca, cada etapa de la modernidad capitalista ha dañado de distintos modos (en temporalidades y geografías) y para distintos conglomerados sociales; por su lado, las estructuraciones societales han tenido igualmente variaciones, aunque en esencia, la contradicción estructural ha sido la misma. Repasando experiencias y mundos de vida, la dictadura del capital está volviendo imposible la vida sobre el planeta. Hay que hablar del esquema básico de estructuración societal sin reducir la complejidad de la vida social e individual a uno de sus aspectos. Este modo de civilización se introduce en la estructura de producción de la vida social determinándola crecientemente en todos sus aspectos y formas. La contradicción que aniquila el valor de uso, al embozar la auténtica naturaleza de la mercancía fuerza de trabajo como mercancía simple, causa el primer y más importante daño

${ }^{9}$ Podríamos decir que el daño a la vida en sociedades preclasistas provino de lo Otro, la naturaleza.

${ }^{10}$ A esta estrategia Echeverría la ha denominado ethos, "Ubicado lo mismo en el objeto que en el sujeto, el comportamiento social estructural al que podemos llamar ethos histórico puede ser visto como todo un principio de construcción del mundo de la vida" (Echeverría, 1998: 37). 
social. Este modo capitalista estructuralmente violento se monta sobre la forma natural de la vida y la destruye, la deforma, la aniquila para su propio telos; su violencia primaria es el sacrificio sistemático de la lógica natural de la vida para su propios principios y exigencias, metamorfoseándose, luego, en otras múltiples formas de explotación, en las cuales, la guerra es la realidad básica de su proceso histórico. Resulta, así, una vida dañada por la alienación social y los quiebres de la civilización. Hablamos de las experiencias de hambre, dolor, enfermedad y muerte y de una alienación que va de tomar totalmente para sí parte del cuerpo social (como la moderna captura de esclavos) a la aniquilación de pueblos enteros que no son útiles al sistema del capital. Éste viene acompañado por toda una cohorte de relaciones, instituciones y formas duras de dominio y explotación, hasta dominaciones suavizadas, dispersas o re-localizadas. Las condiciones por las que es insoportable el modo capitalista cultural en nuestra otra modernidad son las de neocolonialismo y colonialidad, las de dependencia y por ser el insumo. Resulta invivible para todos cuando la precariedad de la existencia mueve la comodidad o estabilidad o, simplemente, cuando se es diariamente miserable por falta de alimento; luego, ya específicamente, al ethos realista, cuando pierde su inversión o sus ganancias o cuando es víctima de la democracia con crimen organizado; al ethos clásico: cuando la respuesta ethoica pierde su referencia o sentido conformista y resignado, cuando debe abandonar su posición de alejamiento y ponerse claramente a favor o en contra y cuando debe ignorar u ocultar la contradicción del valor; al ethos romántico: cuando le resulta imposible privilegiar el valor de uso, cuando debe afirmar o asumir la contradicción del valor, cuando el sistema no puede ser considerado una aventura del espíritu, cuando cae en la cuenta de que el sistema puede ser transformado $y$, por su parte, al ethos barroco: dado que no borra, ni oculta la contradicción del valor, el sistema moderno capitalista le resulta 
siempre odioso e insoportable, así, su respuesta es la resistencia y la rebelión, aún a sabiendas de que oscilará entre el vértigo y la desesperación.

2. Imaginarios sociales y el cuádruplo ethé moderno. En la modernidad cada ethos tendría un tipo específico de imaginario y, si bien hay múltiples modernidades que indican los grados de sujeción a los centros del World-system, éstas se comprenderían en términos de los diferentes imaginarios ethoicos; pero, el a priori material cultural del factum capitalista se interioriza y responde en términos de refugio y arma contra las contradicciones implicadas en cada una. Con esta formulación es claro que la teoría de los ism deja de lado los factores y aspectos centrales que configuran la experiencia y mundos de vida modernos, es decir, las preguntas girarán en torno a si los ism son un tipo de pre-condición que acompaña un acontecimiento cultural societal en toda la unidad de la diversidad de sus componentes, si su sentido estructurante tiene una consistencia tal que permita dicha ocurrencia de prácticas modernas, si la trilogía: economía, esfera pública y vida democrática abarca el plexo completo de las experiencias y mundos de vida modernos. Dicho de otro modo: ¿cuál es el papel de los ism en la dimensión cultural de las sociedades? Donde cultura es el cultivo dialéctico de la singularidad de una forma de humanidad en una circunstancia histórica determinada, una versión particular del código universal de lo humano; o, con otras palabras, cómo el hombre se va haciendo signo y cómo la hominización es un proceso que surge de una codificación universal, la cual se va realizando en cada una de las formas surgidas de subcodificación en lo material concreto. La cultura enfatiza la reconstitución metasemiótica de una figura concreta de subcodificación que tiene ya implícita, no alguna que le viene de fuera, de una teoría moral $\mathrm{u}$ otra. La reafirmación autocrítica del estado de código en que dicha versión se encuentra indica la apertura de su constitución 
y el sentido previo que se va re-sustancializando (cfr. Echeverría, 1998: 161ss). Todos los imaginarios sociales de una época podrían entenderse como versiones particulares del código universal en circunstancias históricas determinadas; pero, entonces, este conjunto es más que un ism, puesto que Taylor no sólo privilegia determinado tipo de imaginarios en la constitución de la modernidad, fragmentando la unidad de la vida social cultural, sino que omite la investigación de aquel a priori, los impulsos históricos sobre los que se interioriza el hecho decisivo de la modernidad. Podríamos ver qué entiende Taylor por cultura y por qué no es relevante en la constitución, difusión y asunción de conjuntos de ideas dadoras de sentido a las prácticas: habla de ésta como la forma global de lo humano, ${ }^{11}$ dejando de lado su significado histórico concreto, lo occidental frente a lo oriental (cfr. Echeverría, 2013: 166), por lo que termina cegado a los recodos complejos de experiencia y mundos de vida. Es la definición restringida de cultura criticada por Echeverría. Para Taylor, diferentes modernidades provienen de diferencias culturales, pero esto queda reducido a las diferencias de ism implicados, sin el a priori material de las fuerzas históricas. En cambio, para Echeverría es que estos diferentes impulsos previos a la interiorización del hecho capitalista, a los que se suma el suyo, le dan forma al ethos histórico moderno resultante, decir esto significa que a las operaciones funcionales capitalistas son concomitantes otras dimensiones de subcodificación que le eran ajenas (funcionales y meta-funcionales), pero que quedan integradas y se expresan en formas de comportamiento y pensamiento en los que se afirma o niega no sólo el hecho de la modernidad, sino la existencia propiamente como tal (Echeverría, 2013: 19). Para el investigador ecuatoriano los ism son sólo uno de los resultados del proceso de codificación y subcodificación que acompaña la pro-

${ }^{11}$ Por ejemplo, en oposición a la cultura Occidental, "reflecting the fact that other non-Western cultures have modernizing in their own way" (Taylor, 2004: 1). 
ducción societal misma, en fin, los ism quedan ubicados en un ámbito secundario, en relación tanto con la producción general de conciencia como con el papel básico de la cultura. Desde otra perspectiva, no es que los imaginarios vayan primero o a la zaga, sino que el hecho capitalista se impone de una forma demoledora tal, que no queda otra que interiorizarlo y darle una respuesta. Ya la actitud de rechazo o aceptación viene con la elección ethoica completa en su unidad crítica de arma y refugio. Con esto, puede verse que los ism no sólo se nutren de una teoría moral sino de todo un plexo de discursividad, en el que destacan ideas asociadas a prácticas interesadas en las condiciones materiales de existencia.

En nivel tayloriano, los imaginarios producidos en América Latina, explican una dudosa modernidad porque incorporan elementos de origen netamente occidental y otros distintos originados en ella y que la han desviado, pero, pensamos que esto ha ocurrido debido al patrón occidental de poder. Tal es el caso de los ism configurados en las condiciones de codigofagia de las Colonias hispanas, imaginarios en estrecha relación formativa con lo que Echeverría denominó la modernidad barroca. Si lo que está en juego es la capacidad conceptual de los ism frente a los ethé, los primeros son ideas que se han materializado de algún modo y cobrado importancia en la influencia de prácticas y su sentido, los ethé, por su lado, son descripciones de tipos diferenciados de experiencia y de los mundos de vida conformados a partir de la estructuración societal moderna. Si para Taylor la hipótesis básica es la centralidad de una nueva concepción del orden moral, para el autor de esta reflexión, es que en el centro de nuestra modernidad barroca se halla una estrategia de supervivencia, un conjunto de elementos ethoicos como respuesta al devoramiento de sus propios códigos - y mundos - previos, pero, de algún modo aún presentes hasta el día de hoy. En los que está igualmente la impronta de toda una cauda de traumas, complejos y problemas (unos ya resueltos, otros 
en vía de serlo y otros totalmente nuevos), se trata, en efecto, no sólo de una configuración más compleja de imaginarios con las funciones ya dichas, sino en forma decisiva de la imposición de un nuevo esquema de cultura, que viene acompañado por una gama amplia de ideología y que entra en conflicto con otra ya existente y en condiciones de desventaja.

También, apunta Taylor, que en los ism occidentales los humanos son seres racionales y sociales cuyo destino es colaborar entre ellos para beneficio mutuo, idea que habría ido ganado terreno en nuestro pensamiento político y nuestra forma de imaginar la sociedad (cfr. Taylor, 2004: 3). Hay que considerar cómo esta idea se materializa en la vida de las sociedades no occidentales y los diferentes discursos sobre ella, sus puntos de partida, de apoyo factual y teórico, es decir, enfocarse en el problema de la «consistencia». La idea de orden moral ha experimentado una doble expansión (Taylor, 2004: 5), pero también ha experimentado otra doble expansión: por un lado, en extensión, su falsedad respecto de los espacios y de los contenidos realmente existentes, ocultando que la práctica produce otro imaginario desde el combate contra la desigualdad y la discriminación; por otro lado,en intensidad, con el advenimiento del cinismo de la posmodernidad (Echeverría, 1997: 40). Si cada nueva redacción del imaginario es más rica y exigente es porque hay otros factores que la nutren, como imaginarios relacionados con la utopística, proveniente de la «negación determinada», en la cual su contenido es intencionadamente provisional o negativo. Aquí hay que dirigir la vista a la teoría del poder, que significa como experiencia a los imaginarios propios de las dominancias societales y los de aquellos que sobreviven en sus galeras. En el caso de México, nuevas redacciones de ism son más exigentes cada vez, porque la irracionalidad inherente al orden social cultural se recrudece como resultado de nuestro propio quiebre civilizatorio, en el cual el sistema-mundo expresa en toda su desnudez el impulso 
histórico del lucro a toda costa. Es importante que en respetarnos y servirnos unos a otros es decisivo el elemento del intercambio económico, empero ¿qué damos y que obtenemos en éste? Además, este intercambio, forzado para la periferia, lo tiene en desventaja, pues se trata de que en un lado está la no-civilización, a la que hay que salvar introduciendo el impulso cultural del capital. Ya que son imaginarios centrales: los económicos (nuevo mercado resultará en el bienestar general) y los políticos (la igualdad general), el nuevo tipo de cultivo cientista (nueva vida con todos los problemas resueltos), son los más proclives a la fetichización. Lo que nos lleva al problema de la relación, imaginarios y sus modos de encubrimiento, de fetichización, de hipostasiación, de influencia en las acciones que reifican la vida social. Estos contenidos de los ism para América Latina se han quedado en promesas, debido a la índole engañosa del patrón de dominación que hemos sufrido y que en la modernidad viene como un paquete completo de relaciones de poder de todo tipo: militar, institucional y su propia dimensión cultural de la vida social (lo que Aníbal Quijano denominó "colonialidad del poder") ${ }^{12}$. Para el grupo de Mignolo, Grosfoguel, et al., más que estar básicamente en un factum capitalista estamos en un factum civilizatorio interseccionalizado, o bajo heterarquía, o de heterogeneidad histórico estructural, presa de una amplia gama de relaciones de poder, una de cuyas respuestas es la insurgencia epistémica proporcionada desde cosmogonías no occidentales, lo cual, no desentona con el pensamiento de Echeverría, pues, de las categorías marxistas que maneja no se entiende que, resolviendo el problema de la valorización del valor se resuelve el resto de la problemática social (Echeverría, presenta una versión de paquete completo de la modernidad con su concepto de cultura, al que entiende como un sistema/civilización, (cfr. 2013: 163ss.); más

${ }^{12}$ El concepto de 'colonialidad del poder', fue presentado por Quijano en 1991 y de una forma más acabada en 2000: 202- 242. Ver, especialmente p. 209. 
bien, las categorías que emplea se dirigen a explicar que de la supervivencia - la producción de valores de uso- depende el resto de la reproducción societal (Echeverría ni siquiera pensó que hubiese una solución como salida del capitalismo). ${ }^{13}$ Hay que aclarar que es cierto, como lo considera este grupo de investigación, que la categoría de última instancia significa de otra manera, los países no eurocéntricos harán lo que les dicta la dominancia eurocéntrica, ya sea por convencimiento, ya sea por la fuerza militar (Grosfoguel, 2010: 27'20"ss.; 62' 50”'ss.).

Libertad y beneficio mutuo quedaron en el terreno de lo que está por cumplirse cabalmente, no sólo debido al patrón de dominación sino por las desviaciones e inconsistencias co-provocadas, como la globalización y el posmodernismo. Estos incumplimientos se han tornado complejos por diversas regresiones, nuevos actores y fenómenos sociales como el resquebrajamiento y surgimiento de subcodificaciones, entre otros. Existe otro tipo de constitución de imaginarios que va en el sentido inverso, se trata de los contra imaginarios, uno de cuyos temas es: qué es lo que hace, efectivamente, que las cosas no funcionen como relaciona el ism y el porqué de sus desviaciones. Para Taylor, el background que da sentido a las prácticas carece de límites claros, pero, porque debe ser elástico para poder adecuarse con las prácticas y darles sentido dentro de la idea madre del eurocentrismo, main repository of civilization. Por ello, los ism son una comprensión en gran medida inarticulada (porque son sobreentendidos — tratándose de un código del que surgen diversas subcodificaciones) en el marco de la cual se manifiestan los rasgos particulares de nuestro mundo tal como son, sólo que desde la mira de la dominancia cultural. Nunca pueden expresarse adecuadamente en forma de doctrinas, son ilimitados e indefinidos por naturaleza, pero deben por fuerza articularse en

13 Por ello, el ethos barroco "no contiene ninguna tendencia anticapitalista" (Gandler, 2007: 417), citando a Bolívar Echeverría. 
algún momento como formas de dominación. Un contrasentido que aclara esto es que si hay algún modo de resistencia y rebeldía por parte de los dominados el centro del sistema/mundo opone el sentido totalitario del poder militar.

¿Hay un imaginario social que subyace a la teoría de Bolívar Echeverría, un orden moral, tanto en el terreno de la utopística como en el del 'aquí y ahora'? ¿Qué interpreta y qué prescribe? Para el ethos barroco, no se trata tanto de un ism como de una resignificación que teatraliza una realidad invivible (pone en escena la posibilidad de la existencia en ruptura); de algún modo tiene un trasfondo moral, pero no es compartido por grandes estratos sociales sino todo lo contrario; interpreta, resignificándolo, dicho factum capitalista porque ha de seguir existiendo, prescribe y actúa en rebeldía, resistiendo. Veamos esto un poco más de cerca.

\section{El imaginario social propio del ethos barroco}

Es opuesto al ethos realista y comparte algo con los ethé romántico y clásico. ¿Qué es lo simbólico en cada uno? Aquello que da sentido a su resolución cultural, dará la respuesta a en qué consiste el imaginario de cada uno de los ethé, no sólo modernos sino de cada una de las épocas conocidas de la humanidad. Éste es el alcance explicativo universal de la teoría de la cultura de Bolívar Echeverría. El ethos realista ama absolutamente la acumulación y no le importa ninguna otra cosa (no hay contradicción existencial); el ethos romántico transfigura y distorsiona en su contrario este conjunto imaginario (hay la contradicción pero es empatizable); para el ethos clásico su ideal es el alejamiento de la contradicción, sin desconocer el sacrificio que conlleva. Esta breve caracterización debería servir para delinear el perfil del ethos barroco. Dos palabras que lo definen son resistencia y rebelión. Algunas de sus características son: no contiene tendencias anticapitalistas; es una respuesta espontá- 
nea que pisa el terreno de la reflexión, a diferencia de los otros ethé cuya respuesta a la interiorización de las contradicciones sociales es espontánea; aspira a la recuperación del valor de uso como centro de la producción, reproducción de la vida social; reconstruye su experiencia del mundo de la vida a partir de las ruinas dejadas por la destrucción del valor de uso; cree que una suma de voluntades ethoico barrocas puede oponerse al factum capitalista. La estrategia del ethos barroco es social y aparece con la colonización del mundo precolombino y la necesidad resultante del mestizaje hacia el siglo XVII. Su principal fondo u horizonte de surgimiento no es tanto una teoría moral sino la necesidad de supervivencia de los sujetos de la colonización y de la necesidad de los colonizadores de tener una parte del cuerpo social a su disposición: mutua codigofagia en una dialéctica de señor/siervo.

\section{El imaginario de la libertad. Background como Urteilskraft $y$ como moral}

¿En qué medida el pensamiento crítico necesita de ism? Éste ha partido del estudio de las contradicciones de los mundos de vida y su práctica no requiere de un background inarticulado que le de sentido, sino de un auténtica calidad y sensibilidad morales. Se funda en la crítica de lo que es: de la negación del hecho cultural capitalista y de las posibilidades reprimidas por éste. Es decir, de los impulsos y fuerzas históricas que han quedado subsumidas y negadas por dicho factum. Quizá lo primero en la formación crítica de imaginación de libertad — la proyección bajo control de alternativas posibles y la necesidad de pensar en otro telos- ${ }^{14}$ es que requiere de un tipo distinto de ser humano del que domina. De modo que hay dos escenarios posibles situados en los extremos:

${ }^{14}$ Ver Horkheimer y Adorno, (2005: 231). Comentan la idea kantiana de que la proyectividad es críticamente justificable. 
por un lado, la visión apocalíptica "tal como lo sentimos en nuestra época postmoderna” (Britt, 2013: 77); por el otro, del lado del principio crítico de esperanza (de Kant a Bloch) necesita creer que la especie camina hacia su mejoramiento, que el siguiente salto será hacia su moralización "una esperanza negativa [...] que se detenga el desorden moral [...] que genera toda la violencia que amenaza a la humanidad con guerras perpetuas, la destrucción tecno científica de la biósfera y el empobrecimiento cultural de los seres humanos" (Britt, 2013: 87).

\section{E. Epilogo}

Lo que está en juego en la modernidad es el dilema que propone Nietzsche con el problema del espíritu dionisiaco y que sigue en su fondo como código background, a pesar de la dominancia apolínea, que significa que lo abierto-reprimido dionisiaco puede saltar en cualquier momento como la liebre de Hegel (determinabilidades tan complejas que son impredecibles en sus alcances para desviar el locus del conflicto inherente a la existencia como experiencia y mundos de vida). La crítica del principio del eurocentrismo justifica la teoría de Echeverría, puesto que su concepto de múltiples modernidades presenta: la imagen completa, lo que es y su negación. En Echeverría, el eje central de explicación de lo moderno es la imagen teórica de la cultura, una abstracción construida a partir de lo concreto y sus especificidades, un eje múltiple que se mueve en un esquema filosófico crítico: cultura, producción/ consumo, funcional/metafuncional. La idea de crítica en su definición de cultura indica lo abierto en contraste con el comportamiento de los ism, es decir, la permanente crisis de los mundos de vida versus la solidez de los ism que se desvanecen en el aire "no mode of modernism can ever be definitive" (Berman, 1988: 6). El ethos barroco busca la contingencia histórica, pensar múltiples modernida- 
des, temporalidades y geografías. Bolívar Echeverría habla sobre lo que nos hace la modernidad a nosotros: su negación determinada del referente empírico expresa la imagen de lo crítico de la cultura, a la inversa de la incapacidad de los ism; los conceptos del ethos histórico nos dicen en qué consisten los tipos de experiencia de lo moderno; los lados oscuros de la modernidad se podrían agrupar bajo la noción de quiebres de la civilización; los ism negativos son nuevos imaginarios de ruptura, más complejos en su constitución y vigencia. No obstante, hablar de ism re-coloca en el centro los problemas y la polémica de la moral. Para terminar, ¿cuál puede ser el sentido crítico de los ism? Originan modernidad y son originados dentro de modernidad; los cambios sociales implican mutuamente cambios de ism, lo mismo que las sociedades complejas implican mutuamente ism complejos. Finalmente, ¿cuál posición teórica responde más satisfactoriamente qué es lo típicamente moderno, su concepto clave? (Kozlarek, 2012: 51). Vale por ahora.

\section{Bibliografía}

Agustín, San , 1963, Obras III (obras filosóficas), Madrid, Biblioteca de Autores Cristianos.

Beck, Ulrich, 1997, ¿Qué es la globalización? Falacias del globalismo, respuestas a la globalización, Barcelona / Buenos Aires/México, Paidós.

Berman, Marshall, 1988, All that is solid melts into the air. The experience of modernity, Penguin Books.

Britt Arredondo, Christopher, 2013, "De la Casa de Salomón a la Research University", Valenciana, nueva época, año 6, núm. 11 (enero-junio), pp. 69-89.

Castoriadis, Cornelius, 2013, La institución imaginaria de la sociedad, Barcelona, TusQuests. 
Castro-Gómez, Santiago y Ramón Grosfoguel, 2007, El giro decolonial: reflexiones para una diversidad epistémica más allá del capitalismo global, Bogotá, Siglo del Hombre.

Echeverría, Bolívar, 1976, "Discurso de la revolución, discurso crítico”, Cuadernos Políticos/ERA, núm. 10 (octubre-diciembre), pp. 44-53.

, 1997, Las ilusiones de la modernidad, México, UNAM / El Equilibrista.

, 1998, La modernidad de lo barroco, México, ERA.

, 2012, Valor de uso y utopía, México, Siglo XXI.

, 2013, Definición de la cultura, México, Ítaca/FCE.

Gandler, Stefan, 2007, Marxismo crítico en México: Adolfo Sánchez Vázquez y Bolivar Echeverría, México, FCE/UAQ.

Girola, Lidia, 2007, "Imaginarios socioculturales de la modernidad. Aportaciones recientes y dimensiones del análisis para la construcción de una agenda de investigación”, Sociológica, año 22, núm. 64 (mayo-agosto), pp. 45-76.

Grosfoguel, Ramón, 2010, "La crisis terminal de la moderni$\mathrm{dad} /$ colonialidad y del pensamiento eurocéntrico: la búsqueda de alternativas sostenibles al sistema-mundo actual", Universidad de Granada, (16 de diciembre). Disponible en: http:// www.dailymotion.com/video/xg8zb7_ramon-grosfoguel-lacrisis-terminal-de-la-modernidad, duración 1:11:45.

Horkheimer, Max y Theodore W. Adorno, 2005, Dialéctica de la Ilustración. Fragmentos filosóficos, Juan José Sánchez (Intro., trad.), Madrid, Trotta.

Kant, Immanuel, 2005, Crítica de la razón práctica, Dulce María Granja Castro (trad., estudio prel., notas e índice analítico), México, FCE/ UAM / UNAM.

, Critica de la razón pura, Pedro Ribas (pról., trad., notas e índices), Madrid, Taurus. 
Kozlarek, Oliver, 2012, "Debates actuales en torno de la modernidad. Perspectivas y horizontes", Acta sociológica, núm. 59(septiembre-diciembre), pp. 33-53.

Marx-Engels, 1971, La ideología alemana, en Obras escogidas en tres tomos, t. I, Moscú, Progreso, pp. 11-81.

Quijano, Aníbal, 2000, "Colonialidad del Poder, Eurocentrismo y América Latina”, en Edgardo Lander (ed.), Colonialidad del saber y eurocentrismo, Buenos Aires, UNESCO-CLACSO, pp. 201-246.

Taylor, Charles, 2004, Modern Social Imaginaries, Durham y Londres, Duke University Press.

Wagner, Peter, 2012, Modernity. Understanding the Present, Cambridge, Polity Press.

(Artículo recibido el 7 de enero de 2014; aceptado el 25 de febrero de 2014) 